\title{
BRASIL COMO MIEMBRO NO PERMANENTE DEL CONSEJO DE SEGURIDAD DE LAS NACIONES UNIDAS EN EL MANDATO 2010-2011
}

\author{
Carlos Enrique Ruiz Ferreira \\ Alexandre César Cunha Leite
}

\section{INTRODUCCIÓN $^{1}$}

Se Eligió de nUevo a Brasil el 15 de octubre de 2010 para un mandato de dos años (del 1 de enero de 2010 al 31 de diciembre de 2011) como miembro no permanente del Consejo de Seguridad. En la elección, el país obtuvo 182 votos entre 183 votantes, con que fue elegido junto a Bosnia-Herzegovina, Gabón, Líbano y Nigeria. Dentro de los términos de la Carta de las Naciones Unidas, el Consejo de Seguridad tiene como responsabilidad primaria velar la paz y la seguridad internacional, teniendo en cuenta la prerrogativa de determinar y señalar cualquier amenaza a la paz, rupturas de acuerdos o actos de agresión, según consta en el artículo 39. Es en el ámbito del Consejo de Seguridad que se deciden las medidas que serán tomadas para combatir tales amenazas, inclusive por medio del establecimiento de operaciones de paz, como la MINUSTAH.

El objetivo de este artículo es analizar la actuación de Brasil como miembro no permanente del Consejo de Seguridad durante 2010 y 2011, destacando sus prioridades y haciendo un balance de

${ }^{1}$ Este artículo fue realizado en el marco del proyecto de investigación "La política exterior brasileña en el Consejo de Seguridad de la onU en la pos Guerra Fría”, financiado por el Consejo Nacional de Desarrollo Científico y Tecnológico (CNPq) de Brasil. 
algunas cuestiones centrales en este periodo. Por medio de las cuestiones más relevantes de la política internacional del periodo y de las actuaciones y prioridades de la agenda brasileña, se eligieron las siguientes cuestiones o problemas durante el periodo por discutir: 1) el papel de la minustah, 2) el conflicto Israel-Palestina, 3) las cuestiones africanas, 4) la reforma del Consejo de Seguridad, 5) el acuerdo nuclear Brasil-Turquía-Irán y 6) la posición sobre Libia. Además, al último, se ofrece una breve discusión sobre la alianza G-4, teniendo en cuenta la estrategia de Brasil para la obtención de un asiento permanente en el Consejo de Seguridad de la ONU.

Lo que se busca aquí es una sistematización de la actuación de Brasil como miembro no permanente del Consejo de Seguridad durante 2010 y 2011, con el objetivo de identificar una sintonía entre las directrices esenciales de la política exterior brasileña, que sustentan sus discursos y acciones, y las verdaderas actitudes brasileñas al enfrentarse a situaciones de política internacional que demandan su postura. El análisis de los hechos y de los posicionamientos brasileños delante de las cuestiones enlistadas en este artículo nos lleva a creer que la política exterior brasileña representa continuidad en lo que toca a sus principios diplomáticos. La actuación de Brasil y sus posicionamientos consecuentes ante las cuestiones mencionadas tienen como objetivo, más allá de colocarse para proyectar una imagen de protagonista en los grandes temas de la agenda internacional, enviar al sistema internacional el mensaje de que el país reúne las condiciones para ejercer una función más representativa, aspirando, sobre todo, a los grandes foros internacionales, entre ellos el Consejo de Seguridad de las Naciones Unidas (en adelante csonU).

Este artículo se divide en cuatro partes. En primer lugar, se traza un breve historial de la actuación de Brasil en la onU, en particular, dado el enfoque del artículo, como miembro no permanente del Consejo de Seguridad. En seguida, se discuten las cuestiones catalogadas como relevantes tanto para la política internacional como para la definición de la postura brasileña y sus votos respectivos en el cSONU. En la tercera parte se vuelve la atención hacia la demanda brasileña hacia una reforma de la onU, en especial del Consejo de 
Seguridad, en busca de un asiento permanente en ese foro. Por último se presentan las consideraciones finales.

\section{Un Recuento del país en el Consejo de Seguridad Y LA ELECCIÓN RECIENTE}

Brasil participó en los esfuerzos militares para la derrota del Eje, tomando parte inclusive, en 1945, en la Conferencia de San Francisco, con que figuró en la lista de los 51 países fundadores de la Organización de las Naciones Unidas (ONU). Estados Unidos llegó a contemplar al país para formar parte del Consejo de Seguridad como miembro permanente, si bien, desde luego, sus ambiciones se desplomaron ante otras potencias. Desde esta época Brasil apoya con bastante estabilidad (pese a los distintos regímenes desde entonces) a la onU, respetando el principio fundamental de la diplomacia brasileña de respeto y promoción del multilateralismo.

Cuando se revisa la participación de Brasil en el Consejo de Seguridad como miembro no permanente, es decir, como nación con derecho a voto pero no a veto, se constata que el país completa diez mandatos, a saber: 1946-1947, 1951-1952, 1954-1955, 1963-1964, 1967-1968, 1988-1989, 1993-1994, 1998-1999, 2004-2005 у 2010-2011, con que figura junto con Japón entre las naciones con mayor número de mandatos como miembro no permanente en el csonu.

Se debe destacar que la participación de un país como miembro no permanente no permite una participación efectiva en los procesos de decisión. A fin de cuentas, compete sólo a los cinco miembros permanentes la posibilidad de veto. En la práctica, por tanto, Francia, Estados Unidos, China, Reino Unido y Rusia son los países que toman las decisiones en el ámbito del Consejo. A Brasil, y a todos los miembros no permanentes, toca "apenas" pronunciarse, haciendo uso de la palabra para justificar su voto, que puede ser a favor, en contra o abstención. Los beneficios de esta participación, de esta suerte, deben medirse dentro de esta estructura oriunda de la etapa inmediatamente posterior a la Segunda Guerra Mundial. No obstante, es preciso considerar que una participación, bien que no decisiva, permite, si no influir en algunos 
casos, hacer pública y notoria la postura diplomática de un país y fortalecer su participación en el escenario internacional, lo que permite aumentar su prestigio y liderazgo regional.

Uno de los ejemplos más notables es la participación de Brasil en las operaciones de paz. Aunque para contribuir a una operación no sea necesario formar parte del Consejo, esto facilita su acceso. Desde el punto de visto histórico, el país tomó parte, con tropas, en la primera misión de paz de las Naciones Unidas en 1956 en el Canal de Suez, y suma, a la fecha, una contribución activa con más de 17000 personas (entre tropas, diplomáticos y técnicos) en 33 operaciones de paz. Los datos de julio de 2014 de las Naciones Unidas revelan que entre las dieciséis operaciones llevadas a cabo por la Organización, Brasil participa en un total de nueve, con más de 1686 efectivos, en tres continentes, con que ocupa el lugar 21 de los países que contribuyen con tropas. ${ }^{2}$

\section{La actuación de Brasil en el Consejo de Seguridad} (2010-2011) CONFORME A LAS PRIORIDADES DEL PAÍS Y LAS TEMÁTICAS RELEVANTES DE LA POLÍTICA INTERNAGIONAL

Las prioridades de Brasil pueden reconocerse en discursos diversos, declaraciones oficiales (statements) y votos durante su periodo de actuación como miembro no permanente en el Consejo de Seguridad. Con todo, entre los temas de la agenda internacional y los grandes problemas planteados por el csONU en el periodo delimitado en este artículo, se destacan, para fines del análisis: la estabilidad en Haití, el conflicto en Medio Oriente, la cooperación con los países africanos y, no menos importante, la reforma del Consejo de Seguridad. Otras materias, también objeto de debates y posiciones, ganaron importancia debido al contexto internacional y, fundamentalmente, a causa de posturas y decisiones tomadas por Brasil y de las repercusiones de tales posturas, como: la cuestión nuclear en Irán, el acuerdo Brasil-Irán-Turquía y los conflictos en Libia. De esa forma, en esta parte se pretende evidenciar las actuaciones

${ }^{2}$ United Nations Peacekeeping: http://www.un.org/en/peacekeeping/ 
de Brasil en el csonu concernientes a los temas de mayor envergadura durante el bienio para el país.

\subsection{Haití y el papel de la MINUSTAH}

Haití es la primera república negra libre el continente latinoamericano. Su independencia data de 1804, con que se convirtió en nación libre, aunque con altos índices de pobreza extrema. La historia política de Haití registra, considerando el último golpe de Estado, 34 golpes políticos. Tras el paso de François Duvalier (Papa Doc) y de Jean-Claude Duvalier (Baby Doc), que sumaron una dictadura de 29 años, la situación política haitiana avanzó poco. Con la caída de Jean Bertrand Aristide no hubo elección que trajese estabilidad política al país.

Durante esa situación, antes que Haití se convirtiese en un caso clásico de statefailure, ${ }^{3}$ el csonu, por medio de la Resolución REs/1529/2004, estableció una Fuerza Multinacional Provisional, comandada inicialmente por Estados Unidos. Considerando la presencia de problemas internos y externos, que incluyen la campaña contra el terrorismo y la necesidad de una mayor presencia

${ }^{3}$ Helman y Ratner definieron en 1993 los "failed states" como "utterly incapable of sustaining itself as a member of the international community" ("Saving Failed States", Foreign Policy, 89, invierno de 1992-1993, p. 3) El término, polémico, sigue siendo debatido. Según la definición más reciente de Foreign Policy, que produce el Failed State Index (http://ffp.statesindex.org/), un Estado fallido se identifica por una serie de características (transformadas en indicadores para medición): "One of the most common is the loss of physical control of its territory or a monopoly on the legitimate use of force. Other attributes of state failure include the erosion of legitimate authority to make collective decisions, an inability to provide reasonable public services, and the inability to interact with other states as a full member of the international community" (Foreign Policy, FAQ, 2013). Foreign Policy trabaja con doce indicadores de riesgo que cubren: "extensive corruption and criminal behavior, inability to collect taxes or otherwise draw on citizen support, large-scale involuntary dislocation of the population, sharp economic decline, group-based inequality, institutionalized persecution or discrimination, severe demographic pressures, brain drain, and environmental decay" (Foreign Policy, FAQ, 2013). 
en el territorio haitiano con la intención de restaurar las condiciones de gobernabilidad, se creó la Misión de Estabilización de las Naciones Unidas en Haití (MINUSTAH).

Brasil aceptó liderar la minustaH, creada por la Resolución RES / 1542/2004. El liderazgo y el compromiso activo de Brasil en el proceso son controvertidos en lo que atañe a la tradición diplomática y a los intereses del país. Aunque la referida resolución menciona el capítulo viI de la Carta, que trata sobre las fuerzas de "imposición de paz", y aunque Brasil sea tradicionalmente escéptico a tales intervenciones, la cancillería brasileña entiende que se trata más de una fuerza de "mantenimiento de la paz" y que la referencia al capítulo viI se restringe apenas a las cuestiones de seguridad. Por estos y otros motivos, hubo una oposición considerable en el Congreso Nacional al alistamiento del país en la Misión. Además de las manifestaciones contrarias del Congreso Nacional, sectores de los medios tradicionales y conservadores, más algunos sectores de la izquierda y la extrema izquierda, se presentaron como críticos contumaces de la actuación brasileña. ${ }^{4}$

La minustah prosiguió y se amplió, notablemente luego de que acontecieran los desastres naturales en el país (huracanes 2008 y terremoto en enero de $2010^{5}$ ), de modo que la reconstrucción del país se volvió una prioridad de la a Misión. Brasil se responsabiliza por el Comando Militar de la Misión constituyéndose en el país con el mayor contingente de tropas en Haití (más de 2000 efectivos). Aparte de su contribución a la Misión de la onu, el país donó también 55 millones de dólares al Fondo de Reconstrucción

${ }^{4}$ Para una discusión pormenorizada de la interpretación con relación al capítulo viI, así como sobre la posición de los partidos políticos en el Congreso, véase Eugenio Diniz, "O Brasil e a minustaH”, 2005, en http:// www.cprepmauss.com. br/documentos/obrasileaminustha98283.pdf En su artículo, Diniz resalta que la propuesta del Ejecutivo Federal encontró críticas incluso de parte de los congresistas del Partido dos Trabalhadores y, luego de idas y vueltas, "la materia se aprobó por votación simbólica, sin registro de votación individual” y que se trató de una "decisión claramente top-down del gobierno brasileño" (Diniz, op. cit., p. 104).

${ }^{5}$ Véase el Decreto Legislativo núm. 75 del 25 de enero de 2010, que autoriza el aumento de 900 hombres en el efectivo brasileño en la MINUSTAH en función del terremoto del 12 de enero de 2010. 
de Haití del Banco Mundial, mantiene programas de cooperación técnica en diversas áreas y destinó recursos considerables (por medio de fondos adicionales) para que varios ministerios establecieran proyectos y acciones encaminados a Haití. En el ámbito de la Unasur, Brasil apoyó una serie de decisiones tomadas después del terremoto, que incluyen ayuda humanitaria, eliminación de aranceles de importación, estímulo a las inversiones que utilicen gran cantidad de mano de obra en el país y la creación de una Comisión dentro del Consejo de Defensa para dar seguimiento a las decisiones.

Sobresale que, a ojos de la onU, la MinustaH confiere gran responsabilidad al liderazgo brasileño. Pero, adicionalmente, atrae visibilidad para Brasil ante los países interesados en la solución del problema haitiano. El liderazgo de Brasil en la MinustaH robustece su candidatura a un asiento permanente en el Consejo de Seguridad, dado que el país comienza a involucrarse en acciones del Consejo de Seguridad relacionadas al capítulo vir de la Carta. El objetivo es mostrar a la comunidad internacional que el país está listo para asumir responsabilidades de mayor envergadura. Brasil también se proyecta regional e internacionalmente, asumiendo un comando militar de una misión de relevancia internacional, ampliando, principalmente, su legitimidad en la región sur y latinoamericana.

\subsection{El conflicto Israel-Palestina}

El conflicto Israel-Palestina aparece como un tema recurrente en los debates del Consejo de Seguridad. Brasil defiende un papel más proactivo del Consejo. En este mandato, Brasil propuso una misión del Consejo de Seguridad a la región para averiguar la situación in loco y buscar mejores formas de entendimiento. Cuando se trata de pronunciarse sobre los conflictos en la región, la diplomacia brasileña enfatiza su repudio a las violaciones de los derechos humanos y mantiene su imparcialidad realizando sus críticas a ambas partes, según sea el caso.

$\mathrm{Al}$ repasarse la participación brasileña en la cuestión palestina, se constata que Brasil participó activamente en la cuestión de 
Palestina desde la segunda mitad de la década de $1940 .{ }^{6}$ En las discusiones de las Naciones Unidas el plan de la partición de Palestina se presentó por Osvaldo Aranha, ${ }^{7}$ quien presidía la sesión. El 29 de noviembre de 1947, el Plan para la Partición de Palestina fue votado. El resultado fue de 33 votos a favor, 13 en contra y diez abstenciones. La cuestión palestina sigue con todo inconclusa; aun así Brasil mantuvo su postura presentada en 1947. En cuanto a la cuestión de la legitimidad de la construcción de un Estado Palestino (en los debates del Consejo de Seguridad), Brasil se ubica a favor, argumentando que se trata de una necesidad fundamental para los derechos humanos, la dignidad, la libertad y el desarrollo del pueblo palestino. Ejerciendo una de sus prerrogativas soberanas, Brasil reconoció el Estado Palestino oficialmente el 1 diciembre de 2010, en una carta enviada al presidente Mahmud Abás, de la Autoridad Nacional Palestina (ANP). El reconocimiento de Brasil se realizó con base en la delimitación territorial de 1967, antes de la Guerra de los Seis Días, lo que exacerbó los descontentos de algunos líderes israelíes. ${ }^{8} \mathrm{El}$ gobierno de Lula desde su inicio presentó una política activa en lo que concierne a Palestina: la designación en 2004 de un embajador en Ramala, la participación brasileña en la Cumbre del ASPA (América del Sur-Países Árabes)

${ }^{6}$ Véase Roche, “O Oriente Médio e as relações diplomáticas internacionais”, en Paulo Visentini (org.), A Grande Crise: a nova (des)ordem internacional dos anos 80 e 90, Petrópolis, Vozes, 1992; y Fred Halliday, The Middle East in International Relations: Power, Politics and Ideology, Cambridge, Cambridge University Press, 2005. Ya Gomes ("A questão da Palestina e a fundação de Israel”, tesis de maestría, Departamento de Ciência Política da Universidade de São Paulo, 2001) resalta el juego de poder entre las naciones durante la Guerra Fría. Los intereses de la URSS, de Gran Bretaña y de Estados Unidos eran condiciones relevantes en las decisiones geopolíticos de la región. Con todo, los intereses de las llamadas petromonarquías también deben considerarse cuando se trabaja con temas relacionados a la región de Medio Oriente.

7 Político brasileño, abogado, fue ministro de(Justicia (1930-1931), de Hacienda (1931-1934, 1953-1954) y de Relaciones Exteriores (1938-1944). En 1947 fue nombrado jefe de la delegación brasileña en las Naciones Unidas y representó el país en el asiento de miembro no permanente en el Consejo de Seguridad.

${ }^{8}$ Paulo Fagundes Visentini, A Primavera Árabe: entre a democracia e a geopolítica do petróleo, Porto Alegre, Editora Leitura XXI, 2012. 
en 2005 y el encuentro personal de Lula con Mahmud Abás parecen respaldar una propuesta diplomática brasileña para Israel. De acuerdo con Cecília Baeza, ${ }^{9}$ Lula entendía a Palestina como una puerta de entrada al mundo árabe.

Maihold afirma que el paso del presidente Lula en 2010 por la región (Israel, Palestina y Jordania) representó una fase nueva en la diplomacia presidencial practicada por Brasil desde Lula. ${ }^{10}$ Sin embargo, el mismo autor resalta, para fines de la reflexión, que se trata de un gran desafío para la diplomacia brasileña: "el alto nivel de violencia y las múltiples dimensiones de la conflictividad en Oriente Medio son de una índole a la que no está acostumbrado Itamaraty y representan terrenos desconocidos, o poco trabajados, en el marco de la política exterior brasileña". ${ }^{11}$

Cabe, mientras tanto, notar que Brasil no está solo en la comunidad internacional en lo que se refiere al reconocimiento del país. En sus alianzas nuevas y antiguas, los países BRICs (Brasil, Rusia, la India y Sudáfrica) e IBAs (la India, Brasil y Sudáfrica) reconocen a Palestina; y en el ámbito del Mercosur, el bloque celebró en diciembre de 2011 un acuerdo de libre comercio con Palestina, demostrando su apoyo político al Estado.

\subsection{Relaciones Brasil-África: un énfasis en la cooperación}

El continente africano ha ascendido en su estatus en el escenario internacional. Las relaciones exteriores de los países africanos vienen creciendo, específicamente cuando se refiere a los países emergentes. Entre estas relaciones destacan las de cooperación internacional, siguiendo la propuesta acordado de cooperación Sur-Sur. De acuerdo con el argumento de Saraiva, "el continente africano asiste a una

${ }^{9}$ Cecília Baeza, "O Reconhecimento do Estado Palestino: origens e perspectivas”, Meridiano 47, vol. 12, núm. 126, jul.-ago. de 2011, pp. 34-42.

${ }^{10}$ Gunther Maihold, “¿Demasiado mundo?: Lula, Brasil y Oriente Medio”, Real Instituto Elcano, 2010, en http:/ / www.realinstitutoelcano.org/wps/wcm/connect/ bd096e804204da87b185bd1233cb485b/AR622010_Maihold_Brasil_oriente_medio_Lula.pdf?MOD=AJPERES\&CACHEID=bd096e804204da87b185bd1233cb485b

11 Ibid., p. 6. 
transición positiva hacia un nuevo nivel de inserción internacional al inicio del nuevo siglo". ${ }^{12}$

Tal argumento, sostiene el autor, se apoya en tres grandes líneas de acciones y cambios en el escenario africano actual, a saber: 1) hay un avance gradual en los procesos de democratización, considerando los antiguos regímenes políticos y los conflictos armados de la región; 2) hay un crecimiento económico relacionado por un lado a la asociación estratégica con países en proceso de desarrollo, como Brasil y China, ligado a reformas económicas, principalmente de carácter fiscal; y 3) la elevación de autoconfianza de las élites por medio de nuevas formas de renacimientos culturales y políticos. ${ }^{13}$

En el periodo anterior al gobierno de Lula, predominaba en Brasil, al igual que en diversos países desarrollados, una asociación errónea entre África y el atraso, conflictos y gobiernos no democráticos. Como observa Saraiva, "la reflexión acerca de los desafíos africanos es modesta y tardía. Pero llegó comprometida en los últimos años". ${ }^{14}$

La posición de Brasil, en lo que se refiere a su política exterior, considerando el periodo señalado en este artículo, se clasifica como activa por el propio gobierno. En lo que concierne a los casos más específicos de la acción de política exterior brasileña, se puede destacar, en primer lugar, el trabajo en dirección de GuineaBissau. El país sufre de una inestabilidad política histórica y ocupa uno de los últimos lugares en el Índice de Desarrollo Humano. ${ }^{15}$ En ese sentido, Brasil tiene un compromiso notable. Cuando el continente africano adquirió mayor dimensión en la agenda de la política exterior brasileña, en el inicio del gobierno de Lula, Guinea-Bissau ocupó un lugar prominente. Se pueden señalar las

12 José Flávio Sombra Saraiva, África parceira do Brasil atlântico: relações internacionais do Brasil e da África no início do século XXI, Belo Horizonte, Fino Traço, 2012.

${ }^{13}$ Loc. cit.

14 Ibid., p. 54.

15 De acuerdo con el Índice de Desarrollo Humano de 2014 del PNud, Guinea-Bissau ocupaba el lugar 177 entre los 187 países analizados. Como uno de los últimos países de la lista, se lo considera un país con bajo desarrollo humano, al lado de Haití, Burkina Faso y Mali. Véase http://hdr.undp.org/en 
visitas del ministro Celso Amorim y del presidente Lula a ese país en 2005; también cuando para la Cumbre de la Comunidad de Países de Lengua Portuguesa (CPLP), en 2006, Brasil apoyó con vehemencia su celebración en este país; y, en diciembre de 2007, cuando Brasil pasó a coordinar la configuración de la Comisión de Consolidación de Paz (CCP) de la onu para Guinea-Bissau.

La delegación brasileña en la Comisión de Seguridad reiteró que la onu debería comprometerse con el desarrollo económico e institucional del país y la construcción y mantenimiento de la paz. Brasil fue uno de los participantes en la preparación del proyecto de Resolución res/2030/2011, aprobado por unanimidad, para prolongar el mandato del Gabinete Integrado de las Naciones Unidas para la Consolidación de la Paz en Guinea-Bissau (Uniogbis, por sus siglas en inglés) hasta febrero de 2013. Sin embargo, la cancillería brasileña discutió reforzar el papel de la CPLP, de la Unión Africana y de la Comunidad Económica de los Estados de África Occidental (Ecowas, según el acrónimo inglés) para el desarrollo y la paz del país.

En el caso de Sudán del Sur, Brasil se sumó a los otros catorce miembros del Consejo de Seguridad a favor de la recomendación hecha a la Asamblea General para el reconocimiento de este nuevo país africano (REs/1999/2011). Sudán del Sur se separó de Sudán, como una región marcada por conflictos intensos y frecuentes que se remontan desde la invasión turco-egipcia que posteriormente se sumó a la ocupación británica (en el s. xIx). El propio proceso de independencia de este país fue escenario de una disputa entre los colonizadores, lo que llevó, desde la creación del Estado en 1956, a crisis políticas y militares. Se sumaron a los efectos nefastos de la colonización las pugnas de la Guerra Fría. La población de la región sur de Sudán, desde los albores de la independencia, no se reconocía como parte del Estado ni del gobierno sudanés debido a las razones mencionadas (la colonización y las consecuencias de la Guerra Fría); a tales razones se agregan cuestiones de orden religioso que dieron origen a una guerra civil que duró más de cuatro décadas. ${ }^{16}$ En 2004, el conflicto en Darfur se

${ }^{16}$ De acuerdo con Isiaka Badnus: "Sudán es comúnmente señalado como un 
consideró como un genocidio por unos y como crisis humanitaria por otros. El Consejo de Seguridad y la Unión Europea iniciaron sanciones, si bien los conflictos prosiguieron.

Por fin, la Resolución de 2011 del Consejo de Seguridad se adoptó sin votación el 13 de julio, pocos días después de la declaración de independencia de Sudán del Sur y el reconocimiento de Brasil, que había ocurrido el 9 de julio. El 14, luego de la aprobación de la Asamblea General de la onu, el país se convirtió en un nuevo miembro del sistema de la onU.

\subsection{La reforma del Consejo de Seguridad}

La posibilidad de Brasil para ocupar una vacante en el Consejo de Seguridad apareció desde los comienzos de la onU, dada la propuesta del presidente Roosevelt. En términos contemporáneos, en los marcos de las discusiones recientes en el ámbito de las Naciones Unidas, Brasil lanzó oficialmente su candidatura en 1994, en la XLIX Sesión Ordinaria de la Asamblea General de la ONU (AG-ONU), por intermedio del embajador Celso Amorim, entonces ministro de Relaciones Exteriores de la administración de Itamar Franco.

En lo que toca al bienio que destacamos (2010-2011), el tema de la reforma se hizo frecuente en los debates del Consejo de Seguridad. Estos debates se desarrollan en torno a dos asuntos: uno más general, sobre la participación de nuevos miembros permanentes y no permanentes y la consecuente ampliación o no de los vetos; el otro se puede clasificar como más específico, sobre el modus operandi del Consejo de Seguridad. Sobre la primera cues-

\footnotetext{
'microcosmos de África' que queda entre las fronteras de diferentes mundos culturales: África árabe/África afriacana, África musulmana/África cristiana y África anglófona/ África francófona". (Sharif Harir, "Recycling the Past in the Sudan: An Overview of Political Decay", en Sharif Harir y Terje Tvedt [eds.], Short-cut to Decay: The Case of the Sudan, Uppsala, Nordiska Afrikainstitutet, 1994, p. 10). Este forzado crisol de árabes musulmanes y africanos negros agobia a la política sudanesa desde la independencia (A. Ali Mazuri, "The Multiple Marginality of the Sudan", en Y. F. Hassan, [ed.]. Sudan in Africa, Khartoum, Khartoum University Press, 1985, p. 240).
} 
tión, Brasil defendió una serie de posiciones y principios en el bienio. Una de las más frecuentes (que se expondrá de nuevo en la sección tres de este artículo) trata sobre la defensa de una mayor representatividad internacional en el Consejo de Seguridad. Así, el Consejo de Seguridad habría de incluir la presencia de nuevos miembros permanentes. El argumento para justificar esta idea, no tan nueva, es simple: la composición del Consejo de Seguridad todavía refleja las consecuencias de la Segunda Guerra Mundial y parece imperativo que este órgano se atienda el orden internacional contemporáneo. Ganar representatividad política y económica de las naciones emergentes debe ser contemplado por la organización, especialmente en sus órganos decisorios. Esta ampliación concedería mayor representatividad a los miembros de la comunidad internacional, a la vez que elevaría la legitimidad al órgano y a sus respectivas decisiones. En este ámbito, los países en desarrollo, o países del Global South, deberían ser más representados.

La segunda cuestión, que no se encuadra directamente en el cuadro teórico de la alta política (high politics), se refiere a la reformulación de los métodos de trabajo del Consejo de Seguridad. La cancillería cree en la pertinencia de una gestión más participativa del órgano. Brasil propone la creación y el fortalecimiento de los espacios de interlocución con los demás órganos del sistema de la ONU, así como la realización de consultas permanentes a todos los miembros del Consejo de Seguridad sobre los temas de la agenda. También se demanda una mayor promoción del diálogo con los países que son blanco de debates y resoluciones por parte del Consejo de Seguridad. En ese sentido, volver públicas las sesiones del Consejo de Seguridad (todas de ser posible, sin perjuicio de consultas y reuniones reservadas entre los miembros) y establecer mecanismos de monitoreo de las acciones para el cumplimiento de las resoluciones adoptadas (en particular de aquellas que autorizan el uso de la fuerza) son acciones que garantizarían más credibilidad y legitimidad al órgano. 


\subsection{El acuerdo nuclear Irán-Brasil-Turquía: incidencia brasileña} en el hard power de las relaciones internacionales. ¿Éxito o fracaso diplomático?

La cuestión nuclear de Irán ganó un espacio significativo en la agenda de las relaciones internacionales de 2010-2011, y sigue teniendo repercusión. En lo que atañe a esta cuestión, Brasil se destacó nuevamente como jugador global (global player) al promover el acuerdo, junto con Turquía, firmado por Irán, por el que este país se comprometía a enviar parte de su uranio para ser enriquecido en el exterior. Firmado el 17 de mayo de 2010, el acuerdo se efectuó teniendo en cuenta un acuerdo previamente propuesto por la Agencia Internacional de Energía Atómica (AIEA) en octubre de 2009 .

El drama, más inmediato, que envuelve a esta cuestión nuclear es que, por un lado, la comunidad internacional quiere la garantía de Irán de que su programa nuclear tiene finalidad pacífica, y, por el otro, requiere la aceptación por parte del país para que se realice la transferencia de buena parte de sus existencias de uranio para ser enriquecido (al 20\%) no en su propio suelo, sino en otra nación, de preferencia Rusia o Francia. Irán atendió estas demandas de las grandes potencias nucleares (en particular Estados Unidos, Reino Unido y Francia), salvaguardadas por la AIEA, en el acuerdo promovido por Brasil y Turquía. No obstante, Estados Unidos, Francia y el Reino Unido no quedaron satisfechos con los compromisos asumidos por Irán y promovieron la aprobación de la Resolución 1929 en el csonu, con sanciones para el país. Brasil votó contra la resolución, junto a Turquía, declarando que el acuerdo celebrado por los tres países superaba los obstáculos políticos existentes hasta entonces y hacía posible la materialización de la propuesta de la AIEA de octubre de 2009.

El acuerdo firmado trajo fuertes repercusiones políticas para Brasil. En un reportaje difundido por el periódico Folha de São Paulo el 25 de mayo de 2010, se presentó el discurso de descontento de Estados Unidos ante el acuerdo firmado entre Brasil, Turquía e Irán. La secretaria de Estado de Estados Unidos, Hillary Clinton, expuso públicamente la contrariedad del Estado norteamericano 
con Brasil a causa del anuncio del acuerdo. En un discurso en Washington, teniendo como tema la Estrategia de Seguridad Nacional de la Casa Blanca, al ser cuestionada sobre Brasil, Hillary dijo: "Ciertamente tenemos discordancias muy serias con la diplomacia brasileña en lo refrente a Irán. Expresamos al presidente Lula y al ministro [Celso] Amorim (Relaciones Exteriores) que ayudar a Irán a ganar tiempo y evitar una posición internacional unánime contra su programa nuclear vuelve al mundo más peligroso". ${ }^{17}$ De ese incidente surgen dos análisis provechosos sobre el caso. En primer lugar, la diplomacia brasileña puede considerarse victoriosa en ese episodio por el simple hecho de que ella alcanzó sus objetivos concretos, o sea, la promoción de un acuerdo que fortalecería la seguridad internacional. Además, la diplomacia brasileña y turca no puede juzgarse por el fracaso del acuerdo, en vista de que no se trataba de su jurisdicción exclusiva; fueron las potencias ya citadas las que desacreditaron el acuerdo. De esta suerte, sería ingenuo aceptar el cambio de foco tan común en los análisis sobre el caso, que, en vez de repudiar las posturas de las potencias nucleares, que claramente optaron por ignorar un acuerdo de naturaleza única en el escenario internacional, condenaron la actuación de la cancillería brasileña. En la lectura atenta de los discursos de la época, de Francia, Reino Unido y Estados Unidos, no hay ningún rechazo de orden concreto y técnico contra el acuerdo conjunto. También, a juzgar por los discurso y entrevistas concedidas en aquellos momentos por el canciller Amorim y por el presidente Lula, el acuerdo había sido discutido previamente con los liderazgos de las grandes potencias y concretado con base en los acuerdos de la AIEA de 2009.

En una ocasión, el ministro Celso Amorim dijo: "Escuchamos a todos, conversamos con los franceses, con los americanos, con los rusos, con los chinos. Entonces, en realidad, tenemos plena confianza de cuáles son y cuáles eran los problemas. Es claro que nosotros no estábamos negociando en nombre de ellos. Negociábamos con la conciencia de las cuestiones y preocupaciones que

${ }^{17}$ Folha de São Paulo, 25 de mayo de 2010. 
ellos tienen". ${ }^{18}$ Por tanto, la conclusión más plausible es la de que Brasil había conseguido una conquista importante, junto con Turquía, para la comunidad internacional en lo que se refiere a la seguridad internacional, mostrándose capaz de ejercer un protagonismo responsable en materia de seguridad nuclear global. No obstante, estos esfuerzos y esta conquista no se asumieron satisfactoriamente por el concierto de las naciones más poderosas del mundo. Al final y al cabo, toca a la diplomacia brasileña reflexionar sobre el caso.

Por fin, cabe recordar que la cuestión nuclear en las relaciones internacionales contemporáneas fue tratada, con la firma del Tratado sobre la No Proliferación de las Armas Nucleares (TNP), según dos pesos y dos medidas: el tratado cristalizó jurídicamente la división de los Estados en dos categorías, a saber: los Estados nucleares que poseen bombas nucleares y la tecnología para su fabricación, y los no nucleares. Estos últimos deben abstenerse de poseer tecnología para la fabricación de armas nucleares, en tanto que aquellos deben (o debieran) disminuir gradualmente sus arsenales a lo largo de los años.

Sin embargo, no hay razón que justifique que los Estados que poseen armas nucleares las sigan poseyendo. Más aún, la delegación brasileña expresó esta crítica en algunas ocasiones en la onU, ${ }^{19}$ y con base en ella, aunque no solamente por ella, la opción brasileña de no firmar el TNP duró bastante tiempo, hasta el gobierno de Fernando Henrique Cardoso. Otro hecho polémico y que corrobora cierta incredulidad en la moralidad de la cuestión nuclear tratada en los foros oficiales es que, por más que algunos países ya hayan abandonado sus proyectos militares nucleares (como Libia en 2003), otros países se hicieron nucleares al final de los años noventa, como la India y Paquistán.

18 Ibid., 17 de mayo de 2010.

${ }^{19}$ Carlos Ferreira y Elias Martínez, "O multilateralismo da política externa brasileira na ONU”, en Henrique Oliveira y Antonio Lessa (orgs.), Parcerias estratégicas do Brasil, Editora Argvumentum - Fino Traço, 2013. 
2.6. La tradición diplomática, los derechos humanos y la soberanía en el caso libio

Otro caso polémico de la actuación de Brasil en el csonu en el bienio señalado fue el voto de abstención en la Resolución 1793, que autorizó el uso de la fuerza en Libia con la zona de exclusión aérea (no-fly zone), entonces gobernada por el coronel Muamar Gadafi. La resolución citada estaba amparada por lo que se acordó en llamar la Responsabilidad de Proteger (Responsibility to Protect, RtoP o R2P, siglas en inglés), una versión contemporánea que trata del deber de la comunidad internacional de salvaguardar una población civil cuando sus derechos humanos fundamentales (principalmente aquellos relacionados al respeto a la integridad física) están amenazados por su propio Estado.

El escenario libio es complejo y políticamente inestable. Libia es un país rentista, o sea un país que se mantiene económicamente de las ganancias extraídas de una actividad económica no productiva, normalmente extractiva, en este caso el petróleo. ${ }^{20}$ Por cuenta de esa dependencia, la agenda internacional libia se reduce a acompañar las políticas para fijar el precio del petróleo. Ese mercado se sitúa en una circunstancia bastante favorable, desde el punto de vista histórico contemporáneo, en vistas de la escalada en el precio internacional del petróleo y su forma oligopólica de fijación del precio. Los rendimientos originarios de esa actividad permitieron a Gadafi la adopción de una postura beligerante interna y en la región. De acuerdo con Balta, ${ }^{21}$ Gadafi emprendió una serie de hostilidades e intervenciones militares en países vecinos sostenido con los rendimientos del petróleo. Esa condición favorable se sumó a una disposición para generar conflictos regionales y amenazar los intereses de las potencias occidentales, con

${ }^{20}$ Ferrán Izquierdo Brichs, "Poder y estado rentista en el mundo árabe", $R e$ vista de Estudios Internacionales Mediterráneos, núm. 2, mayo-agosto de 2007, en http://www.uam.es/otroscentros/TEIM/Revista/reim\%202/Ferran_Izquierdo_ art.htm

${ }^{21}$ Paul Balta, El Gran Magreg: desde la independencia hasta el año de 2000, Madrid, Siglo XXI, 1994. 
que caracterizó su política exterior como poco cooperativa y propensa a un aislacionismo progresivo.

No quedan dudas de que el régimen libio comandado por el coronel no podría considerarse como un régimen democrático a la manera occidental y de que la situación de Libia, ya entonces, estaba bastante convulsa, rayando en la guerra civil. Rebeldes combatientes y manifestantes políticos sufrieron una dura represión por parte del régimen, lo que resultó, inclusive, en varias muertes. La Liga Árabe y la Unión Africana condenaron públicamente las acciones del gobierno libio, llamando la atención sobre la violación de los derechos humanos. La coyuntura era extremadamente delicada y daba lugar a que algunas potencias (Estados Unidos y Francia) pudiesen proponer una Resolución más incisiva. Con todo, es importante mencionar al menos que los intereses de estos países en la Resolución no eran sólo humanitarios. Ya es conocimiento común el hecho de que hubo y hay varios países en el mundo en situaciones calamitosas en lo que se refiere a derechos humanos, y, curiosamente, no surge ningún interés humanitario de parte de las potencias. Al mismo tiempo, no se puede negar la existencia de los intereses económicos y geopolíticos de las potencias en esta región africana.

Cautelosamente, la declaración de voto de Brasil no trató sobre estos aspectos, y sí reconoció y condenó las acciones de las autoridades libias con relación a las violaciones a los derechos humanos ocurridos en el país. Mientras tanto, su conclusión fue que aún era necesario apostar por el diálogo y que existía la posibilidad de que las medidas adoptadas por la onu provocarían más daños que beneficios a la población civil. En este sesgo tomó cuerpo el concepto promovido por Brasil de la Responsabilidad de Proteger, que hace mención exactamente del peligro de que, con una intervención, se agrave el conflicto entre las partes litigantes y que los civiles sean más perjudicados.

Este nuevo concepto también sirve para auxiliar y legitimar la postura tradicional de la diplomacia brasileña de optar, en casos de esta naturaleza, por la no injerencia, la no intervención. Incluso cuando los países presentan señales claras de que existen violaciones a los derechos humanos, Brasil se muestra escéptico en cuanto 
a las intervenciones militares. Al final y al cabo, en la balanza de los principios que se refieren al derecho internacional, Brasil se inclina más hacia el respeto a la soberanía (la no injerencia y respeto a la integridad territorial) de lo que para los derechos humanos, cuando lo que está en juego son casos en que una intervención militar se coloca como una fuerte opción. El voto de abstención brasileño se sumó a otros cuatro, de países que son parte de algunas de las nuevas alianzas estratégicas de Brasil: Alemania, ${ }^{22}$ la India, China y Rusia.

\section{La estrategia de Brasil para conquistar un asiento permanente en el Consejo de Seguridad}

Las idas y vueltas sobre la posibilidad de un asiento permanente para Brasil en el Consejo de Seguridad se remontan a los comienzos de las Naciones Unidas. Desde la perspectiva contemporánea, inmersa en las discusiones sobre la reforma de la onU y, en particular, del Consejo de Seguridad, la cancillería brasileña demostró su interés explícito y oficial a un asiento permanente en el Consejo de Seguridad en 1994, en la xuIx Sesión Ordinaria de la Asamblea General de las Naciones Unidas de la onu. Para ser merecedor de un asiento, aparte de las credenciales diplomáticas de costumbre, el país también alega que posee dimensiones continentales, una población relativamente grande y una economía de gran porte. Además de esto, es frecuente en la narrativa oficial que Brasil representaría a la región latinoamericana.

En los últimos años, no obstante, la política exterior del presidente Lula y, actualmente, de la presidenta Dilma se distingue por una actuación más protagonista y constante en el escenario

22 De acuerdo con Peterke ("Alemanha em má companhia com os Estados BRIC? A abstenção alemã da Resolução 1973 de 2011 do Conselho de Segurança da onu", Meridiano 47, vol. 12, núm. 125, mayo-junio de 2011, pp. 46-52), la abstención alemana trajo consternación en el escenario europeo, especialmente en los aliados más próximos, como Francia. Con todo, según Peterke, tal incomodidad fue causada debido a que la política exterior alemana se guía por los principios de confianza y defensa de la libertad. 
latinoamericano, especialmente en América del Sur. Cabe recordar los esfuerzos para la construcción de la Unasur y el fortalecimiento del Mercosur, considerando la relevancia de la región y su respectivo ascenso en el escenario internacional. La participación y la diversificación de las acciones y alianzas es, sin duda, una característica única de estas administraciones. En el ámbito internacional el país actuó de forma innovadora, desde su Cooperación Internacional para el Desarrollo ${ }^{23}$ hasta la formación de alianzas como el G-4, el G-20, el ibas y BRIcs, entre otras. Por un lado, no podemos inferir, con todo, que todo este "movimiento" se realice buscando única y exclusivamente un lugar en el Consejo de Seguridad. Por otro lado, son políticas que ayudan a proyectar a Brasil internacionalmente, robusteciendo sus aspiraciones en lo que toca al asiento permanente en el csonu.

De las alianzas internacionales citadas, la que se alinea directamente a los intereses de Brasil en el csonu es el G-4. El grupo,

${ }^{23}$ Datos de la Ayuda Oficial para el Desarrollo de la Organización de Cooperación y Desarrollo Económico (OCDE) en relación a los datos del Instituto de Investigación Económica Aplicada (IPEA, por sus siglas en portugués) de Brasil muestran que Brasil, a partir de 2009 se convirtió en donador internacional en el campo de la ayuda internacional (Amanda Rossi, "Brasil, um país doador", Le Monde Diplomatique Brasil, 1 de abril de 2011, http://www.diplomatique.org.br/ artigo.php?id=910). La mudanza paradigmática refleja una política consciente, de acuerdo con el entonces ministro Celso Amorim: la cooperación Sur-Sur "es un instrumento fundamental para la política brasileña [...] para la aproximación entre Brasil y otros países, en especial del mundo en desarrollo" (Celso Amorim, "A cooperação como instrumento da política externa brasileira", Boletim Via ABC. Boletim Eletrônico da Agência Brasileira de Cooperação, junio de 2006, p. 16). De acuerdo con los datos más recientes (IPEA, "Cooperação Brasileira para o Desenvolvimento Internacional - 2005-2009”, Instituto de Pesquisa Econômica Aplicada, Brasilia, 2010, en http://www.abc.gov.br/api/publicacaoarquivo/328), Brasil gastó en 2010923 millones de dólares en su cooperación internacional. Las regiones en que Brasil ubicó más recursos, dentro de la cooperación bilateral, son América Latina (con $68.06 \%$ de los gastos) y el continente africano (22.58\%). Cuando se destacan los países, se percibe que Haití recibió casi $50 \%$ de toda la ayuda destinada a América Latina y que, en el caso de los países africanos, los que más recibieron fueron las naciones de la Comunidad de Países de Lengua Portuguesa (CPLP), lo que comprueba, una vez más, una actuación pragmática y coherente con sus propósitos. 
creado en 2004 y formado por Alemania, Brasil, la India y Japón, tiene como objetivo central presionar una reforma del Consejo de Seguridad en que sus miembros sean contemplados con un asiento permanente en el órgano. La estrategia del G-4 es influir, a partir del peso político y económico de sus miembros, en los países y en la ONU para producir una discusión más intensa al respecto de una necesaria reforma en el csonu. A despecho de las heterogeneidades encontradas en los países del grupo, las acciones políticas y económicas en el ámbito internacional han promovido alianzas y apoyo en favor de una reformulación del csonu.

No obstante, existe resistencia al G-4. Otros grupos de países se han formado para de la misma manera buscar algún tipo de reforma del Consejo de Seguridad. Es el caso de la Unión Africana y del grupo Uniting for Consensus (UfC). Este último es más problemático para Brasil, pues entre sus miembros figuran países de América Latina de relevancia internacional, como Argentina, México y Colombia. El UfC defendió, en un comunicado conjunto de 2005, la ampliación del número de miembros no permanentes de diez a veinte, procurando los intereses de sus miembros. En su propia propuesta más reciente, de 2009, el grupo considera una nueva categoría de asientos no permanentes: con una duración de 3 a 5 años y no destinados a países sino a grupos regionales. ${ }^{24}$

Para Brasil, la alianza puede considerarse favorable a sus aspiraciones, pues tanto Alemania como Japón son, grosso modo, candidatos con buena aceptación en el concierto de las naciones. La propuesta del G-4 también puede considerarse modesta, porque no prevé cambios significativos en lo referente al statu quo, dado que no se ampliaría el poder de veto para los nuevos miembros permanentes. Los puntos principales de la propuesta son: 1) el Consejo de Seguridad se compondría por 25 miembros; 2) se crearían seis asientos permanentes nuevos; y 3) de estos seis, dos quedarían para países del continente africano, dos para países

${ }^{24}$ Sobre la reforma del Consejo de Seguridad de la onU, véase dos sitios electrónicos donde se trata el tema: Center for UN Reform Education, http://www. centerforunreform.org; y Global Policy Forum, https://www.globalpolicy.org/security-council/security-council-reform.html 
asiáticos, uno para Europa Oriental y uno para la región de América Latina y el Caribe. Con todo, en lo que toca al derecho de veto la propuesta resulta tímida, pues sólo después de quince años de la reforma se considerarían las posibilidades de extender ese derecho a los nuevos miembros.

Se observa que individualmente, por medio de sus acciones en el sistema internacional, Brasil ha venido obteniendo resultados progresivos en su búsqueda de apoyo en el tema del replanteamiento del csonu. También se han empleado acuerdos bilaterales cuando la vía multilateral no rinde los resultados esperados. La evolución de su representación en el continente africano, su mayor participación junto a países asiáticos y su participación en operaciones de paz, allende de su posicionamiento en cuestiones que involucran la seguridad colectiva, muestran un progreso razonable.

\section{CONSIDERACIONES FINALES: PERSPECTIVAS FUTURAS}

El curso reciente de la política exterior brasileña, marcada por una fuerte presencia del Poder Ejecutivo (Presidente de la República), mas amparada en una cancillería tradicional, sólida y fuerte, viene demostrando ser capaz de afirmar a Brasil como actor emergente, protagonista y responsable en las relaciones internacionales. La mayoría de sus acciones externas, aunque sufran críticas por parte de los sectores conservadores nacionales, ${ }^{25}$ se estiman como positivas por la comunidad internacional y por gran parte de la población nacional. Brasil es hoy en día un jugador global (global player) y sus acciones y las opiniones de los máximos representantes del

${ }^{25}$ Como Celso Lafer ("Diplomacia brasileira, novas variações críticas", $O$ Estado de São Paulo, 20 de junio de 2010 http://diplomatizzando.blogspot.com. br/2010/06/criticas-politica-externa-brasileira.html\#sthash.xsdFuRfb.dpuf), Rubens Ricupero (“À sombra de Charles de Gaulle: uma diplomacia carismática e intransferível - A política externa do governo Luiz Inácio Lula da Silva (20032010)", Novos Estudos - Cebrap, núm. 87, 2010, pp. 35-58. http://novosestudos. uol.com.br/v1/contents/view/1389) y Marcos C. Azambuja ("Irã, Turquia e Brasil: Lições do passado e riscos do presente”, Revista Política Externa (São Paulo), vol. 19, núm. 2, sept.-nov., de 2010). 
Estado se tienen en cuenta y se analizan por los más diversos líderes globales académicos dedicados a la política internacional.

Con el análisis de estos seis temas sobre la participación de Brasil en el Consejo de Seguridad, en el mandato 2010-2011, se puede inferir que la diplomacia brasileña se destacó por un protagonismo responsable, pero, sobre todo, pragmático. Al mismo tiempo en que aumentó la inserción internacional en diversas áreas, la cancillería estuvo siempre atenta a la estructura y a la coyuntura internacional, actuando dentro de ciertos límites o constricciones del poder o poderes internacionales.

El protagonismo en la cuestión de Haití y el acuerdo nuclear con Irán y Turquía señalan, sin duda, un activismo innovador. Que Brasil tome parte de una operación de paz, que hace referencia al capítulo viı de la Carta (que se refiere a "fuerzas de imposición"), denota un nuevo estatus del país -polémico, claro está- en el Consejo de Seguridad y en el concierto de las naciones. Además de las críticas que se pueden hacer, Brasil entró en una esfera que, por norma general, es protagonizada por las grandes potencias. $\mathrm{Su}$ postura cambió. En cuanto a Irán, también por primera vez tenemos una actuación diplomática en una cuestión dura (hard), de alta política (high politics), en el escenario internacional. Lidiar con temas nucleares y con un escenario conflictivo que involucra a las naciones más poderosas del planeta es una novedad. Por otra parte, este protagonismo fue responsable: ambas acciones y posturas políticas se hicieron a partir de una intrincada diplomacia y contactos formales con los países involucrados. En lo que atañe a Haití, la incursión brasileña estuvo siempre atenta a la sociedad haitiana y a los consensos en el ámbito de la Unasur, por ejemplo.

En cuanto al continente africano y el Medio Oriente, Brasil siguió un curso más "normal" o tradicional. Ante los países africanos Brasil siguió la alternativa de apostar en la cooperación, con que potenció las relaciones Sur-Sur y ganó legitimidad en este continente. Aunque surjan críticas diversas para este nuevo énfasis brasileño en las relaciones con África, la proyección del país puede potenciarse y no han de subestimarse los logros, que ya suceden, en el dominio económico. El ministro de Defensa, Celso Amorim, en una charla en la Universidad Estadual de Paraíba, reveló que 
"nuestro comercio con África aumentó durante el gobierno de Lula, multiplicándose por cinco", para luego subrayar que "si África fuese un país aislado, en los números de 2008, si no me engaño, sería nuestro cuarto socio comercial". ${ }^{26}$

Por lo que se refiere a Palestina y al caso libio, observamos una postura más cauta, por lo menos en este bienio. Se trató de un no enfrentamiento directo en la cuestión Israel-Palestina, aunque se defendió la creación del Estado Palestino. En Libia, posiblemente la relación entre los gobernantes haya influido en la actuación cautelosa, lo que se suma a una tradición "soberanista" brasileña.

Aunque sea posible hallar algunos puntos críticos en la actuación brasileña, como se vio a lo largo del artículo, se sugiere que existió una postura activa en grandes temas de la agenda internacional. En los casos citados, se reconoce que hay una relación de intercambio que encierra un análisis de costo beneficio. No puede dejar de mencionarse que la actuación de Brasil en Haití, a despecho de su importancia para el país que recibe la asistencia así como para las Naciones Unidas, tuvo éxito, pero el costo político y económico interno ha sido elevado. ${ }^{27}$

Además, casos como las cuestiones iraní y palestina incomodó a los actores involucrados. Se criticó duramente a Brasil por la cúpula política decisoria norteamericana por su involucramiento en la cuestión nuclear de Irán, así como es innegable que hubo un desgaste en la relación con Israel a casusa de la posición brasileña. Sin embargo, eso no puede eclipsar los objetivos mayores relacionados a las directrices de política exterior y las propuestas de actuación de Brasil como global player. Admitimos que toda elección tiene sus costos, y Brasil en el periodo tratado tuvo la habilidad de lidiar con esa relación.

26 Celso Amorim, "Balanço da Política Externa do governo Lula", en Carlos Ferreira (org.), Caderno GAPRI - Edição Celso Amorim. Grupo de Análise Política e de Relações Internacionais, Universidade Estadual da Paraíba, 2012, p. 17, http:// www.uepb.edu.br/download/coordenadoria-de-assuntos-institucionais-e-internacionais/Caderno\%20GAPRI.pdf

27 Ya sea por los gastos económicos, ya por la referencia al capítulo vir de la Resolución que promueve la MINUSTAH. 
En suma, surgen elementos que nos permiten afirmar que un "protagonismo responsable" se evidencia en la actuación de Brasil, aunque esté en formación. Tal postura puede observarse, como se quiso evidenciar en este artículo, durante el mandato 2010-2011 de Brasil en el Consejo de Seguridad. La actuación brasileña en los principales temas de la agenda internacional impulsa la legitimidad y el reconocimiento de Brasil por sus pares, con que se hace más apto para ocupar un asiento permanente en el csonu. En una publicación reciente del Ministerio de Relaciones Exteriores, $B a$ lanço de Política Externa 2003-2010, por ejemplo, se sostiene que el país ya alcanzó una base significativa de apoyos para su intento de figurar en el Consejo de Seguridad como miembro permanente: en este momento se suman 89 de los 192 miembros de la onU para declarar su apoyo a Brasil, de los cuales dos son miembros permanentes del Consejo de Seguridad, Francia y el Reino Unido.

Traducción de Gabriel Ramos

\section{Bibliografía}

Amorim, Celso, "A cooperação como instrumento da política externa brasileira", Boletim Via ABC. Boletim Eletrônico da Agência Brasileira de Cooperação, junio de 2006.

_ -Balanço da Política Externa do governo Lula", en Carlos Ferreira, (org.), Caderno GAPRI - Edição Celso Amorim. Grupo de Análise Política e de Relações Internacionais, Universidade Estadual da Paraíba, 2012, http://www.uepb.edu.br/download/coordenadoria-deassuntos-institucionais-e-internacionais/Caderno\%20GAPRI.pdf

Azambuja, Marcos C., "Irã, Turquia e Brasil: Lições do passado e riscos do presente”, Revista Política Externa (São Paulo), vol. 19, núm. 2, sept.nov. de 2010.

Baeza, Cecília, "O Reconhecimento do Estado Palestino: origens e perspectivas”, Meridiano 47, vol. 12, núm. 126, jul.-ago. de 2011, pp. 34-42.

Balta, Paul, El Gran Magreg: desde la independencia hasta el año de 2000, Madrid, Siglo XXI, 1994.

Badnus, Isiaka Alani, “'Nosso Darfur, Darfur deles': A política desviante 
do Sudão e a nascente 'limpeza étnica' em uma emergente anarquia africana”, Contexto Internacional, vol. 30, núm. 2, 2008, pp. 309-360.

Brichs, Ferrán Izquierdo, "Poder y estado rentista en el mundo árabe", Revista de Estudios Internacionales Mediterráneos, núm. 2, mayo-agosto de 2007, en http:/ / www.uam.es/otroscentros/TEIM/Revista/reim\%202 /Ferran_Izquierdo_art.htm

Congresso Nacional, 2010. Decreto Legislativo $n^{\circ} 75$, de 2010, en http:// www2.camara.leg.br/legin/fed/decleg/2010/decretolegislativo75-25-janeiro-2010-601234-publicacaooriginal-122936-pl.html

Diniz, Eugenio, "O Brasil e a Minustah", 2005, em http:// www.cprepmauss.com.br/documentos/obrasileaminustha98283.pdf

Ferreira, Carlos y Elias Martínez, "O multilateralismo da política externa brasileira na ONU”, en Henrique Oliveira y Antonio Lessa (orgs.), Parcerias estratégicas do Brasil, Editora Argvumentum - Fino Traço, 2013.

Gomes, Aura Rejane, "A questão da Palestina e a fundação de Israel", tesis de maestría, Departamento de Ciência Política da Universidade de São Paulo, 2001.

Halliday, Fred, The Middle East in International Relations: Power, Politics and Ideology, Cambridge, Cambridge University Press, 2005.

Harir, Sharif, "Recycling the Past in the Sudan: An Overview of Political Decay", en Sharif Harir y Terje Tvedt (eds.), Short-cut to Decay: The Case of the Sudan, Uppsala, Nordiska Afrikainstitutet, 1994.

Helman, Gerald B. y Steven Ratner, "Saving Failed States", Foreign Policy, 89, invierno de 1992-1993.

"Hillary critica acordo com Irã e fala em 'sérias discordâncias' com Brasil”, Folha de São Paulo, 22 de mayo de 2010, http://www1.folha.uol. com.br/mundo/741831-hillary-critica-acordo-com-ira-e-fala-em-serias-discordancias-com-brasil.shtml

IPEA, "Cooperação Brasileira para o Desenvolvimento Internacional 2005-2009”, Instituto de Pesquisa Econômica Aplicada, Brasilia, 2010, en http://www.abc.gov.br/api/publicacaoarquivo/328

Lafer, Celso, "Diplomacia brasileira, novas variações críticas", O Estado de São Paulo, 20 de junio de 2010 http://diplomatizzando.blogspot. com.br/2010/06/criticas-politica-externa-brasileira.html\#sthash.xsdFuRfb.dpuf

Maihold, Gunther, “¿Demasiado mundo?: Lula, Brasil y Oriente Medio”, 
Real Instituto Elcano, 2010, en http://www.realinstitutoelcano.org/ wps/wcm/connect/bd096e804204da87b185bd1233cb485b/ AR622010_Maihold_Brasil_oriente_medio_Lula.pdf?MOD=AJPERE S\&CACHEID=bd096e804204da87b185bd1233cb485b

Mazuri, A. Ali, "The Multiple Marginality of the Sudan", en Y. F. Hassan, (ed.). Sudan in Africa, Khartoum, Khartoum University Press, 1985.

Ministério de Relações Exteriores, Balanço de Política Externa, 2003-2010, Brasília, Secretaria de Planejamento Diplomático do Ministério de Relações Exteriores, 2010, en http://www.itamaraty.gov.br/temas/ balanco-de-politica-externa-2003-2010.

"Ministro Celso Amorim não acredita em razoes para novas sanções ao Irã”, Folha de São Paulo, 17 de mayo de 2010, en http://www1.folha. uol.com.br/folha/podcasts/ult10065u736225.shtml

Peterke, Sven, "Alemanha em má companhia com os Estados BRIC? A abstenção alemã da Resolução 1973 de 2011 do Conselho de Segurança da ONU", Meridiano 47, vol. 12, núm. 125, mayo-junio de 2011, pp. 46-52.

Ricupero, Rubens, "À sombra de Charles de Gaulle: uma diplomacia carismática e intransferível - A política externa do governo Luiz Inácio Lula da Silva (2003-2010)", Novos Estudos - Cebrap, núm. 87, 2010, pp. 35-58, en http://novosestudos.uol.com.br/v1/contents/ view/1389

Roche, Alexandre, "O Oriente Médio e as relações diplomáticas internacionais", en Paulo Visentini (org.), A Grande Crise: a nova (des)ordem internacional dos anos 80 e 90, Petrópolis, Vozes, 1992.

Rossi, Amanda, "Brasil, um país doador", Le Monde Diplomatique Brasil, 1 de abril de 2011, http:/ /www.diplomatique.org.br/artigo.php?id=910

Rothkopf, David, The World's Best Foreign Minister, Foreign Policy, 7 de octubre de 2009, en http://rothkopf.foreignpolicy.com/posts/2009/10/07/ the_world_s_best_foreign_minister

Saraiva, José Flávio Sombra, África parceira do Brasil atlântico: relações internacionais do Brasil e da África no início do século XXI, Belo Horizonte, Fino Traço, 2012.

Souza, Bruno y Sabe Bom Meihy Murilo, "Gentileza gera gentileza': o voto do Brasil no Conselho de Segurança quanto à questão da Líbia”, Focus Brasil, 1 de mayo de 2011.

Uziel, Eduardo, O Conselho de Segurança, as Operações de Manutenção da Paz 
e a Inserção do Brasil no mecanismo de Segurança Coletiva das Nações Unidas, Brasilia, FUnAG, 2010.

Visentini, Paulo Fagundes, A Primavera Árabe: entre a democracia e a geopolitica do petróleo, Porto Alegre, Editora Leitura XXI, 2012.

Vigevani, Tullo e Kleinas, Alberto, Brasil-Israel: Da Partilha da Palestina ao reconhecimento diplomático (1947-1949), São Paulo, Cadernos Cedec, 1999. 